\title{
Family planning differentials among religious groups: A study in India
}

\section{Nazish Rasheed, Zulfia Khan', Najam Khalique', Abdul Razzaque Siddiqui', Seema Hakim ${ }^{2}$}

Department of Community Medicine, Hamdard Institute of Medical Sciences and Research, Jamia Hamdard, New Delhi, ${ }^{1}$ Departments of Community Medicine and ${ }^{2}$ Obstetrics and Gynaecology, Jawaharlal Nehru Medical College, Aligarh Muslim University, Aligarh, Uttar Pradesh, India

Address for the Correspondence: Dr. Nazish Rasheed, E-259, Nayyar Manzil Apartments, Jamia Nagar, Okhla, New Delhi - 110 025, India. E-mail: nazish.rasheed@ yahoo.co.in

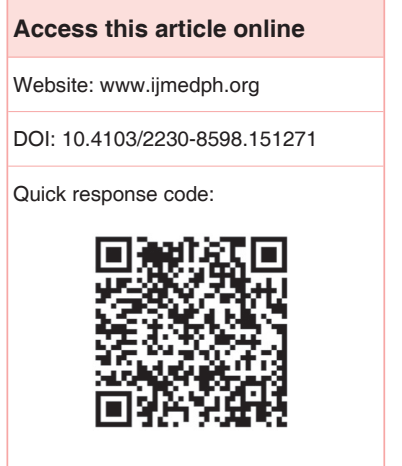

Background: A woman's contraceptive use is largely influenced by the dictates of her religious faith. Acceptance of family planning methods is usually found to be poor among Muslims. This study assesses how acceptance of contraception and contraceptive choices varies across various religious groups. Objectives: (1) To determine the prevalence of contraceptive use among various religious groups. (2) To study the contraceptive use pattern among different religious groups. Materials and Methods: The study was conducted among ever-married women (15-49 years) residing in the field practice areas of Department of Community Medicine, Jawaharlal Nehru Medical College, Aligarh, Uttar Pradesh. The study was a community-based cross-sectional study. Current use and ever-use of contraceptives were assessed among women from various religious groups. The contraceptive choice among current users from different religious groups was studied in relation to use of spacing and terminal methods. Results: Current use of family planning methods was similar for Hindus $(43.1 \%)$ and Muslims (44.1\%). However, ever-use of contraception was found to be more among Muslims (72\%) than Hindus (50.6\%). Spacing methods were more popular among Muslim couples (84.3\%) compared to Hindus (71.7\%), whereas larger number of Hindu couples preferred terminal methods (28.3\%) compared to Muslims (15.7\%). Conclusions: Religion does play a role in the adoption of family planning and the specific method adopted for contraception.

Key words: Contraceptive use, Hindus, Muslims

\section{INTRODUCTION}

The family Welfare Program in India has experienced significant growth and adaptation over the past half-century since its inception in 1951. Several issues continue to daunt the program and many goals remain under-achieved: A significant proportion of pregnancies continue to be unplanned; the contraceptive needs of millions of women remain unmet; several sub-population groups including adolescents and men continue to be neglected and under-served; and contraceptive choice remains conspicuous by its absence, as is quality of care within the program. ${ }^{[1]}$ The extent of acceptance of contraceptive methods still varies within societies and also among different castes and religious groups. The factors responsible for such varied picture operate at the individual, family, and community level with their roots in the socioeconomic and cultural milieu of Indian society. ${ }^{[2]}$ In India, lower contraceptive use rates and higher fertility rates among Muslims than among Hindus and people of "other" religions are well-documented. ${ }^{[3-5]}$ The present study was undertaken with the objectives to determine the prevalence and type of contraceptive usage and among religious groups in rural and urban areas of Aligarh.

\section{MATERIALS AND METHODS}

A community-based cross-sectional study was conducted in the field practice areas of urban and rural health training centers of Department of Community Medicine, Jawaharlal Nehru Medical College, Aligarh, Uttar Pradesh, India. The sample size for the study was estimated using the Couple protection rate as an indicator of the prevalence of contraceptive practice in a population. Sample size was calculated according to couple protection rate of Uttar Pradesh, which was around $38 \%{ }^{[6]}$ using the formula $4 \mathrm{pq} / \mathrm{L}^{2}$. The estimated sample size determined for the study was 718 . 
Ever-married women in the age group 15-49 years present in the household and who gave consent for the interview were included in the sample. On the basis of the household size in the district Aligarh, the average number of ever-married women in the age group 15-49 years was two. To study 718 women, the number of household to be covered was 359 . Taking nonresponse into account the number of households covered were 396. The households in the field practice areas were selected according to the probability proportional to the size.

Systematic random sampling was subsequently done in the respective areas taking into account the calculated sampling interval for each village or urban locality. If the woman was not found in the household, next household was included in the study. Informed consent was taken from the woman prior to the interview. All eligible women in the household were included in the study. The study was conducted over a period of 12 months from August 2007 to July 2008.

A preformed and pre tested structured interview schedule was used for the study which was administered by the researcher to the women. The entire survey was conducted by a team of researcher and medicosocial worker. The proforma was divided into 2 sections; the first section contained baseline information about the woman and her family which included age, religion, caste educational status, education, social class, type of family, age at marriage, number of years of married life, number of children, obstetric history of the woman. Assessment of socioeconomic status was done using the modified BG Prasad's classification. ${ }^{[7]}$ For the purpose of depiction of data, social class II and III were clubbed and are depicted as middle class and social class IV and $\mathrm{V}$ depicted as low class.

The second section contained information about knowledge of family planning method, for assessing attitude of a woman, her husband, and her family members (mother in law). Probing questions were not asked to women whose husbands were not alive or who were separated from their husbands. Regarding practices related to family planning, the woman was methods of contraception she is currently using and methods she had ever used during her lifetime. If more than one method was used, then the latest contraceptive method was taken into account for current use. Ever-use of contraception was considered if the woman has ever used anything or tried in any way to delay or avoid getting pregnant. ${ }^{[8]}$ Current use of contraception was defined as currently married women age 15-49 years who are currently using a contraceptive method or whose husbands are using a contraceptive method. ${ }^{[8]}$ The study was approved by the institutional ethical committee prior to its commencement.

Data compilation, tabulation, and analysis were done using statistical software, SPSS version 16.0 (Chicago, SPSS Inc). The data collected were analyzed using frequencies and percentages, Chi-square test was used to test the significance of the association.

\section{RESULTS}

The basic characteristics of the study population are depicted in Table 1. Majority of the women were in the age group of 20-29 years. The sample had more Hindus than Muslims. Most women were from the general caste category whereas the sample also had women belonging to backward classes and scheduled castes. Literacy status of these women was poor, and a large proportion of them were illiterate. Women were largely from the poor socioeconomic class. Results presented in Table 2; indicate that overall current use of

\begin{tabular}{|c|c|c|}
\hline Background characteristics & Frequency $(n)$ & Percentage (\%) \\
\hline \multicolumn{3}{|l|}{ Age group (in years) } \\
\hline $15-19$ & 43 & 6 \\
\hline $20-29$ & 343 & 47.8 \\
\hline $30-39$ & 218 & 30.4 \\
\hline $40-49$ & 114 & 15.9 \\
\hline \multicolumn{3}{|l|}{ Religion } \\
\hline Hindu & 411 & 57.2 \\
\hline Muslim & 304 & 42.3 \\
\hline Christian & 3 & 0.4 \\
\hline \multicolumn{3}{|l|}{ Caste } \\
\hline General & 326 & 45.4 \\
\hline Scheduled Caste & 150 & 20.9 \\
\hline Other Backward Class & 242 & 33.7 \\
\hline \multicolumn{3}{|l|}{ Education of woman } \\
\hline Illiterate & 422 & 58.8 \\
\hline Primary & 94 & 13.1 \\
\hline Secondary & 164 & 22.8 \\
\hline Graduate and above & 38 & 5.3 \\
\hline \multicolumn{3}{|l|}{ Social class } \\
\hline High & 1 & 1 \\
\hline Middle & 108 & 15.0 \\
\hline Low & 609 & 84.8 \\
\hline
\end{tabular}

Table 2: Current use and ever-use of contraceptives in relation to religion of woman

Current use of contraceptive and religion of woman

\begin{tabular}{lcccc}
\hline Religion & $\begin{array}{c}\text { Nonusers } \\
\boldsymbol{n}(\%)\end{array}$ & $\begin{array}{c}\text { Current } \\
\text { users } \boldsymbol{n}(\%)\end{array}$ & $\begin{array}{c}\text { Not applicable* } \\
\boldsymbol{n}(\%)\end{array}$ & $\begin{array}{c}\text { Total } \\
\boldsymbol{n}(\%)\end{array}$ \\
\hline Hindu & $142(34.5)$ & $177(43.1)$ & $92(22.4)$ & $411(100.0)$ \\
Muslim & $104(34.2)$ & $134(44.1)$ & $66(21.7)$ & $304(100.0)$ \\
Christian & $1(33.3)$ & $2(66.7)$ & - & $3(100.0)$ \\
Total & $247(34.4)$ & $313(43.6)$ & $158(22.0)$ & $718(100.0)$
\end{tabular}

Ever-use of contraceptive and religion of woman

Religion Never users Ever users Total

$\begin{array}{lccc} & n(\%) & n(\%) & n(\%) \\ \text { Hindu } & 203(49.4) & 208(50.6) & 411(100.0) \\ \text { Muslim } & 85(28.0) & 219(72.0) & 304(100.0) \\ \text { Christian } & - & 3(100.0) & 3(100.0) \\ \text { Total } & 288(40.1) & 430(59.9) & 718(100.0)\end{array}$

*Women who are currently pregnant, menopausal, infecund, subfecund, widows, had a hysterectomy or are not cohabiting with their husbands. $\chi^{2}=0.083, \mathrm{df}=2$, $P>0.05$, insignificant, $\chi^{2}=33.365, \mathrm{df}=1, P<0.05$, significant (calculated only for Hindus and Muslims) 


\begin{tabular}{|c|c|c|c|c|c|c|c|c|c|c|}
\hline \multirow[t]{2}{*}{ Religion } & \multicolumn{6}{|c|}{ Spacing methods } & \multicolumn{3}{|c|}{ Terminal methods } & \multirow{2}{*}{$\begin{array}{l}\text { Total } \\
n(\%)\end{array}$} \\
\hline & $\begin{array}{l}\text { Oral contraceptive } \\
\text { pills } n(\%)\end{array}$ & $\begin{array}{c}\text { Male } \\
\text { condom } \\
n(\%)\end{array}$ & $\begin{array}{c}\text { Copper-T } \\
n(\%)\end{array}$ & $\begin{array}{c}\text { Natural } \\
\text { methods } \\
n(\%)\end{array}$ & $\begin{array}{c}\text { Folk } \\
\text { methods } \\
n(\%) \\
\end{array}$ & $\begin{array}{l}\text { Total } \\
n(\%)\end{array}$ & $\begin{array}{c}\text { Female } \\
\text { sterilization } \\
n(\%)\end{array}$ & $\begin{array}{c}\text { Male } \\
\text { sterilization } \\
n(\%)\end{array}$ & $\begin{array}{l}\text { Total } \\
n(\%)\end{array}$ & \\
\hline Hindu & $12(6.8)$ & $74(41.8)$ & $9(5.1)$ & $26(14.7)$ & $6(3.4)$ & $127(71.7)$ & $49(27.7)$ & $1(0.6)$ & $50(28.3)$ & $177(100)$ \\
\hline Muslim & $6(4.5)$ & $94(70.1)$ & $3(2.2)$ & $8(6.0)$ & $2(1.5)$ & $113(84.3)$ & $21(15.7)$ & - & $21(15.7)$ & $134(100)$ \\
\hline Christian & - & $1(50.0)$ & $1(50.0)$ & - & - & $2(100)$ & - & - & - & $2(100)$ \\
\hline Total & $18(5.8)$ & $169(54.0)$ & $13(4.2)$ & $34(10.9)$ & $8(2.6)$ & $242(77.3)$ & $70(22.4)$ & $1(0.3)$ & $71(22.7)$ & $313(100)$ \\
\hline
\end{tabular}

$\chi^{2}=6.152, \mathrm{df}=1, P<0.05$, significant

contraception was $43.6 \%$, current use rates among Hindus and Muslims was almost similar at $43.1 \%$ and $44.1 \%$, respectively. Overall ever-use observed was much higher at $60 \%$. However, there were inter-religion differentials for ever-use of contraception during their lifetime among Muslims and Hindus. This difference in ever-use was found to be statistically significant.

Table 3 shows the type of contraceptive used by women from different religious groups among current users of contraception. It can be observed that spacing methods were much more popular than terminal methods among all women. The adoption of terminal methods like sterilization was less among Muslim women as compared to Hindus. Among temporary methods oral contraceptives, Copper-T, natural methods, and folk methods were more popular among Hindus whereas the condom was the preferred among the Muslims.

\section{DISCUSSION}

Comparable findings for current use have been reported from Mumbai where acceptance of family planning was slightly higher in Muslims than in Hindus. ${ }^{[9]}$ However, country wide conducted national family health survey suggests that the highest contraceptive prevalence rate (CPR) was among Jains followed by Buddhists/NeoBuddhists and Sikhs, these religious groups were not encountered in the present sample. The CPR was 58\% for Hindus and Christians which was more than that found in the present study of Hindus and less than that for Christians. The CPR was 46\% among Muslim women, which was close to the observations of the present study. ${ }^{[8]}$ Contrary to our results, other studies have found lower contraceptive use rate among Muslims. ${ }^{[10-12]}$ District level household survey also reported current use of contraceptives in district Aligarh for any method at $34.5 \%$ which was less than that observed in our study. ${ }^{[13]}$

National family health survey reports have concluded that two-third of currently married women have used a family planning method at some time in their lives which was higher than ever-use found in the present study. ${ }^{[8]}$ Other researchers have also reported higher percentage of ever-users. ${ }^{[14-16]}$

The prevalence of female sterilization was the lowest among Muslims (21\%) reported by national family health survey which was also observed in the present study. The use of pills, intrauterine devices (IUDs), and condoms was higher among Muslims (14\%) as reported by them, whereas only condom was more popular in the present study. Reports of the above national survey further indicated highest use of the traditional method among Muslim and Christian women each whereas the present findings indicate the highest use of traditional methods among Hindus only. ${ }^{[8]}$ Sterilization was the most preferred method among Hindus and condom among Muslims, which was in conformity with the present findings. ${ }^{[11]}$ Results from district-level household survey for Aligarh have reported use of terminal methods, IUD, Oral pill lesser than observed in the present study, however, higher condom use was seen in the current study. ${ }^{[13]}$

\section{SUMMARY}

The current use of contraceptives in the study population was $43.6 \%$. Condom was the most popular method (54\%) of family planning followed by female sterilization (22.4\%), natural methods $(10.9 \%)$. A sizeable percentage $(59.9 \%)$ of women had ever used contraceptives during their lifetime. Maximum number of women had ever used a condom (55.3\%).

Both current use (44.1\%) and ever-use $(72.0 \%)$ of contraceptives was found to be higher among Muslims, the relation between ever-use and religion was statistically significant. The use of contraceptive methods varied with the religion of women, condoms were more used by Muslims (70.1\%).

\section{CONCLUSION}

On the basis of the observations from the present study, we can conclude that current use of contraceptives was almost similar among Hindus and Muslims, though significant differences existed for ever-use of contraceptives among them. As is evident from the results of the study, terminal methods were adopted mostly by Hindus than Muslims, which is reflective of the religious preaching against the use of permanent methods of contraception by Islam. This fact itself should direct us to adopt culture sensitive approaches towards communities and increasing the family planning choices for spacing methods in the basket of family planning program for couples.

\section{REFERENCES}

1. Santhya KG. Changing Family Planning Scenario in India: An Overview of recent Evidence. Regional Working Papers-South and East Asia. New Delhi, India: Population Council; 2003. p. 1.

2. Prateek SS, Saurabh RS. Contraceptive practices adopted by women attending an urban health centre. Afr Health Sci 2012;12:416-21. 
3. National Family Health Survey (NFHS-2), 1998-99: India. Mumbai: International Institute for Population Sciences; IIPS (International Institute for Population Sciences) and ORC Macro; 2000.

4. Ramesh BM, Gulati SC, Retherford RD. Contraceptive Use in India, 1992-93. National Family Health Survey Subject Reports (2). Mumbai: International Institute for Population Sciences; and Honolulu: East-West Center; 1996.

5. Gulati SC. Contraceptive method's use and choice in Kerala and Uttar Pradesh: Multinomial logit analysis of NFHS data. Demogr India 1996;25:205-20.

6. Concurrent assessment and technical assistance, Baseline Facts U. P. Jun 2005-Feb, 2007. RCH \& some other National Health Programmes. Dept. of Medical Health \& Family Welfare. Govt of U.P. \& Upgraded Dept of Community Medicine, KGMU, India.

7. Kumar P. Social Classification-Need for Constant Updating. Indian J Community Med 1993;18:2.

8. National Family Health Survey-3 (NFHS-3, 2005-06), chapter-5, Family Planning, p. 111-60.

9. Joshi SM, Patil SB. Knowledge and practices of family planning in an urban slum of Mumbai. Indian J Prev Soc Med 2007;38:1-2.

10. Singh MM, Khokhar A, Pagare D, Sharma N, Mehra M. A study of contraceptive use among ever-married Muslim women in an urban slum of Delhi. Health Popul Perspect Issues 2003;26:10-5.
11. Kansal A, Chandra R, Kandpal SD, Negi KS. Epidemiological correlates of Contraceptive Prevalence in Rural Population of Dehradun District. Indian J Community Med 2005;30:60-2.

12. Dey S. A study on family planning acceptance among slum dwellers in Shillong, Meghalaya. Indian J Community Health 2014;26:111-4.

13. District Level Household and Facility Survey Under Reproductive and Child Health Project (DLHS-3). Ministry of Health and Family welfare. District Fact Sheet, Uttar Pradesh, Aligarh 2007-08. p. 3.

14. Bhasin SK, Pant M, Mehta M, Kumar S. Prevalence of usage of different contraceptive methods in East Delhi-A cross sectional study. Indian J Community Med 2005;30:53-5.

15. Dabral S, Malik SL. Demographic study of Gujjars of Delhi: IV. KAP of Family Planning. J Hum Ecol 2004;16:231-7.

16. Kabir MA, Khan MM, Kabir M, Rahman MM, Patwary MF. Impact of women's status on fertility and contraceptive use in Bangladesh: Evidence from Bangladesh Demographic and Health Survey, 1999-2000. J Fam Welf 2005;51:1-10.

How to cite this article: Rasheed N, Khan Z, Khalique N Siddiqui AR, Hakim S. Family planning differentials among religious groups: A study in India. Int J Med Public Health 2015;5:98-101. Source of Support: Nil, Conflict of Interest: None declared.

\section{Author Help: Reference checking facility}

The manuscript system (www.journalonweb.com) allows the authors to check and verify the accuracy and style of references. The tool checks the references with PubMed as per a predefined style. Authors are encouraged to use this facility, before submitting articles to the journal.

- The style as well as bibliographic elements should be $100 \%$ accurate, to help get the references verified from the system. Even a single spelling error or addition of issue number/month of publication will lead to an error when verifying the reference.

- $\quad$ Example of a correct style

Sheahan P, O'leary G, Lee G, Fitzgibbon J. Cystic cervical metastases: Incidence and diagnosis using fine needle aspiration biopsy. Otolaryngol Head Neck Surg 2002;127:294-8.

- Only the references from journals indexed in PubMed will be checked.

- $\quad$ Enter each reference in new line, without a serial number.

- Add up to a maximum of 15 references at a time.

- If the reference is correct for its bibliographic elements and punctuations, it will be shown as CORRECT and a link to the correct article in PubMed will be given.

- If any of the bibliographic elements are missing, incorrect or extra (such as issue number), it will be shown as INCORRECT and link to possible articles in PubMed will be given. 